\title{
EL TRATAMIENTO DE LOS CRÉDITOS CONCURSALES Y EL PRINCIPIO PAR CONDITIO CREDITORUM
}

Gabriel A. García Escobar

\author{
Doctorando en Ciencias Jurídicas, Universidad de Granada
}

Email: garciaescobar@ugr.es

\begin{abstract}
RESUMEN
El concurso de acreedores es una institución configurada en el Derecho español a través de la Ley 22/2003, de 9 de julio. Las implicaciones para la esfera económica del deudor insolvente de este régimen especial de cumplimiento de las obligaciones son fundamentales, pero los acreedores también se verán afectados por el procedimiento concursal; su satisfacción dependerá en gran medida de cómo ha configurado el legislador los privilegios concursales y el orden a la hora del cobro de los créditos. Todo ello redundará en un complicadísimo encaje del principio que defiende la igualdad de los acreedores en dicho procedimiento.
\end{abstract}

Palabras clave: concurso de acreedores, deudor insolvente, créditos privilegiados, par conditio creditorum, masa activa/pasiva.

\begin{abstract}
Bankruptcy proceeding is an institution set up in the Spanish law through law 22/2003 of 9 July. The implications for the economic sphere of the insolvent debtor of this special regime of obligations are essential, but creditors will also be affected by the bankruptcy proceedings; their satisfaction depends largely on how the legislator has configured the bankruptcy privileges and the order at the time of the recovery of claims. All this will result in an extremely complicated lace of the principle that advocates equality of creditors in such proceeding.
\end{abstract}

Keywords: Bankruptcy proceeding, insolvent debtor, privileged credits, par conditio creditorum, active/passive mass. 


\section{PREMISA}

En este trabajo se pretende mostrar cómo queda, o mejor dicho, dónde queda -recogido- el patrimonio del concursado durante el procedimiento concursal. Al hilo de esta cuestión, y como colofón a todo lo que se va a exponer, se harán algunas reflexiones sobre la igualdad de los acreedores a la hora del cobro de sus créditos. Sin embargo, hay que hacer una precisión antes de comenzar. Resulta habitual leer que el patrimonio del deudor queda encuadrado en la masa activa del concurso. Esto no es cierto, no por completo. El patrimonio del deudor contiene bienes y derechos, pero también deudas; de manera que será la yuxtaposición de ambas masas lo que dará como resultado el patrimonio del concursado. Coloquialmente se entiende que el patrimonio es igual a la masa activa, sin embargo, aquí solo hay saldos positivos para el deudor, cuando realmente la situación concursal ha venido dada por el exceso de saldos negativos, que también forman parte de aquél.

\section{LA MASA ACTIVA}

\section{Gestión de la masa}

La masa activa, como acumulación de los bienes y derechos del concursado, puede caracterizarse como un patrimonio de ejecución ${ }^{1}$, cuyo destino es servir a la satisfacción de los acreedores que integran la masa pasiva. Dada esta característica finalista de la masa activa, puede inferirse una cierta responsabilidad sobre la gestión de la misma, que algunos autores han identificado con un verdadero deber de gestión eficiente de la masa activa $^{2}$. El destinatario de tal deber sería la administración concursal o el deudor, en función de la limitación a las facultades patrimoniales de este último.

\footnotetext{
${ }^{1}$ AAVV., Sociedades Mercantiles. Memento práctico, Madrid, -coordinado y editado por- Ediciones Francis Lefebvre, 2010, pág. 1261.

${ }^{2}$ Tal deber es identificado como una exigencia inferida de las prescripciones de la LCon que propugnan la continuidad de la actividad económica, por TAPIA HERMIDA, A., "La gestión de la masa activa del concurso", Estudios sobre la Ley Concursal. Libro homenaje a Manuel Olivencia, Tomo IV, Madrid, Marcial Pons, 2004, págs. 4416 y ss.
} 
Si buscamos la justificación a tal deber, podemos encontrar argumentos diferentes: desde la explicación más básica, que relaciona dicha exigencia con la conservación de la masa activa "del modo más conveniente a los intereses del concurso"33; a la más arriesgada, que encuentra como justificación al mencionado deber y a las propias actividades de gestión de la masa activa, una supuesta exigencia de interés general, que hunde sus raíces en preceptos constitucionales, como el artículo 38 CE. De forma que la libertad allí consagrada, reviste al concepto de empresa de cierta coraza constitucional que inclina la normativa hacia la protección de la misma ${ }^{4}$. Esta postura, pese a ser presentada como una finalidad secundaria del procedimiento, no puede ser admisible ya que supone otorgar a ciertos preceptos constitucionales, el estatus de rectores del ordenamiento concursal (que no tienen). Y ello carece de sentido, ya que gracias a la Ley Orgánica para la Reforma Concursal (LORC) se puede en el seno del procedimiento, suspender ciertos derechos fundamentales que tienen un rango superior al artículo $38 \mathrm{CE}$, como por ejemplo el secreto de las comunicaciones (art. 18.3 $\mathrm{CE})$. Admitir por tanto tales ideas sería equivalente a la inobservancia de la jerarquía de las normas constitucionales porque supondría que de una norma de cierto rango, puede dimanar toda una rama del ordenamiento jurídico idónea para configurar otras normas infraconstitucionales, que serían capaces de suspender la aplicación de derechos que tienen una categoría constitucional superior al propio precepto que fundamenta dicho subsistema del ordenamiento.

La posición que se mantiene aquí, es la de un deber de "gestión eficiente de la masa activa", que va a justificarse por la propia satisfacción de los acreedores, lo que redundará en una obligatoria acción en favor de la conservación de la masa. La profesora PULGAR EZQUERRA señala que la finalidad del concurso no es el saneamiento, esto es, el restablecimiento del equilibrio financiero-patrimonial de las empresas, sino la conservación de empresas como medio para satisfacer los intereses de los créditos afectados por la crisis ${ }^{5}$. Quizá ésta sea una postura extrema, pero no deja

\footnotetext{
${ }^{3}$ Artículo 43 LCon.

${ }^{4}$ TAPIA HERMIDA, A., “La gestión...” op. cit., págs. 4418-4422.

${ }^{5}$ PULGAR EZQUERRA, J., “Aprobación de la reforma concursal en el pleno del Congreso ¿cambio de sentido de la reforma”, Actualidad Jurídica Aranzadi, no 58, 22 de mayo de 2003, pág. 4, Epígrafe VI,
} 
señalar una importante realidad: lo primordial en el concurso es la satisfacción de los acreedores; y de ahí proviene el procedimiento para tratar la insolvencia. No obstante, existen razones económico-sociales que han llevado al legislador a tratar de caracterizar la institución concursal como una suerte de pena con pretensión de reinserción (conservación de la empresa). El principio de continuidad de la actividad económicoprofesional se puede entender como un objetivo con suficiente entidad como para ser tratado por separado a la satisfacción de los acreedores. Sin embargo, el primero siempre estará supeditado al segundo; aunque no son incompatibles, al contrario, el legislador trata de llegar al principal a través del secundario. Ésa es la verdadera razón de ser del ejercicio de facultades de gestión sobre la masa activa.

\section{Composición de la masa activa}

a) Regla general: principio de universalidad

Resulta fundamental en este punto, realizar una panorámica sobre la composición de la masa activa del concurso. La Ley Concursal (Ley 22/2003, de 9 de julio) señala las reglas que nos llevan a incluir ciertos bienes y a separar otros, pero, la manera en que lo hace ha dado lugar a diferentes esquemas teóricos. Cada autor realiza una propuesta que no versará sobre lo que compone la masa activa, que está tasado en la LCon, sino en relación al lugar que ocupan los diferentes bienes en esta composición. Por tanto, lo que varía de un sector doctrinal a otro, es la sistemática con la que se trata la cuestión. Aquí se va a realizar un esquema propio, que como podrá comprobarse bebe de diferentes fuentes, aunque no llega a converger totalmente con ningún esquema ya realizado.

En primer lugar, hay que señalar que en líneas generales la masa activa se corresponde con el patrimonio activo del deudor, no obstante, existen algunas variaciones que degradan dicha identidad. El término patrimonio activo se utiliza para

apartado octavo, de la Exposición de Motivos de la Ley (citada por TAPIA HERMIDA, A., "La gestión de la masa activa del concurso", Estudios sobre la Ley Concursal. Libro homenaje a Manuel Olivencia, Tomo IV, Madrid, Marcial Pons, 2004, pág. 4422). 
evitar caer en ese error que antes señalaba de obviar el pasivo del concursado, en torno al concepto de patrimonio, que es amplio.

El artículo 76.1 LCon, establece el principio de universalidad con respecto a los bienes y derechos del patrimonio que conforman la masa activa. Pero existe un régimen de excepciones, supuestos especiales y categorías similares que complican un poco la composición de la masa activa. Tal principio de universalidad será por tanto un primer paso, una aproximación inicial falta de concreción. Para CORDÓN MORENO ${ }^{6}$, este principio es una aplicación del artículo 1911 del Código Civil, que afecta al cumplimiento de las obligaciones todos los bienes del deudor ${ }^{7}$, presentes y futuros. El citado autor identifica los "bienes presentes" del artículo 1911 CC con los "bienes y derechos integrados en el patrimonio del deudor a la fecha de la declaración de concurso" del artículo 76.1 LCon; y los "bienes futuros" (art. 1911 CC) con "los se reintegren al mismo o adquiera hasta la conclusión del procedimiento" (art. 76.1 LCon). Ciertamente podemos encontrar el paralelismo que destaca CORDÓN MORENO, no obstante, tengo algunas reservas en el sentido de aceptar el principio de universalidad en torno a la masa activa del concurso como una aplicación de la responsabilidad patrimonial universal del deudor de nuestro Derecho civil. Hay que destacar (otra vez) que el paralelismo es claro, pero no creo que un régimen sea causa del otro. El Derecho concursal se trata de un agente deformador del Derecho de obligaciones clásico, en este sentido, cualquier parecido con el mismo, es fruto de todo menos de la causalidad. Los motivos que llevan al legislador a configurar tal principio de universalidad se circunscriben a la satisfacción de los acreedores, que seguramente también inspiran el artículo 1911 CC, pero queda claro que en un Derecho que tiene los efectos que estamos describiendo sobre la esfera obligacional del deudor, dicha elección vendrá dada por un razonamiento autónomo, y no por la influencia del Derecho civil en materia de obligaciones.

\footnotetext{
${ }^{6}$ CORDÓN MORENO, F., Proceso concursal, Pamplona, Aranzadi, 2013, pág. 187.

${ }^{7}$ En el tenor literal del artículo 1911 CC y el artículo 76.1 LCon, encuentro un apoyo a la idea de identificar la masa activa con el término patrimonio activo que he utilizado. En ambos artículos se obvia la palabra patrimonio, y se prefiere hablar de bienes y derechos, que realmente son la parte activa del patrimonio, esto es, lo que hemos denominado patrimonio activo.
} 
b) Reglas especiales: esquema básico

Hecha esta primera aproximación a la composición de la masa activa, como todos los bienes y derechos del concursado (patrimonio activo), es aconsejable presentar el esquema que posteriormente se va a desarrollar someramente y que hace perder la identidad entre masa activa y patrimonio activo. El siguiente cuadro debe leerse desde dos ópticas. En primer lugar, los signos positivo o negativo determinan los conceptos que operan sumando o restando sobre el patrimonio activo para obtener como resultado la masa activa del concurso. En segundo lugar, los colores tratan de trasladar una idea más compleja: la pertenencia de los conceptos que se muestran al patrimonio activo del deudor en un estadio cero (en que no ha tenido lugar ningún tipo de acción tendente a aumentar o disminuir la masa). Los cuadros rojos representan conceptos que no forman parte del patrimonio activo del deudor, bien porque no vayan a ser integrados nunca (derechos sin contenido económico), o bien porque sin la correspondiente acción no pueden formar parte del mismo. El color azul expresa que los conceptos así resaltados, y a falta de acciones de terceros que los reivindiquen, forman parte del patrimonio activo del deudor, aunque luego -en función del signo negativo- haya que detraerlos del mismo para obtener la masa activa (a veces por ministerio de la Ley de forma obligatoria, a veces por el ejercicio de acciones de separación de un tercero). 

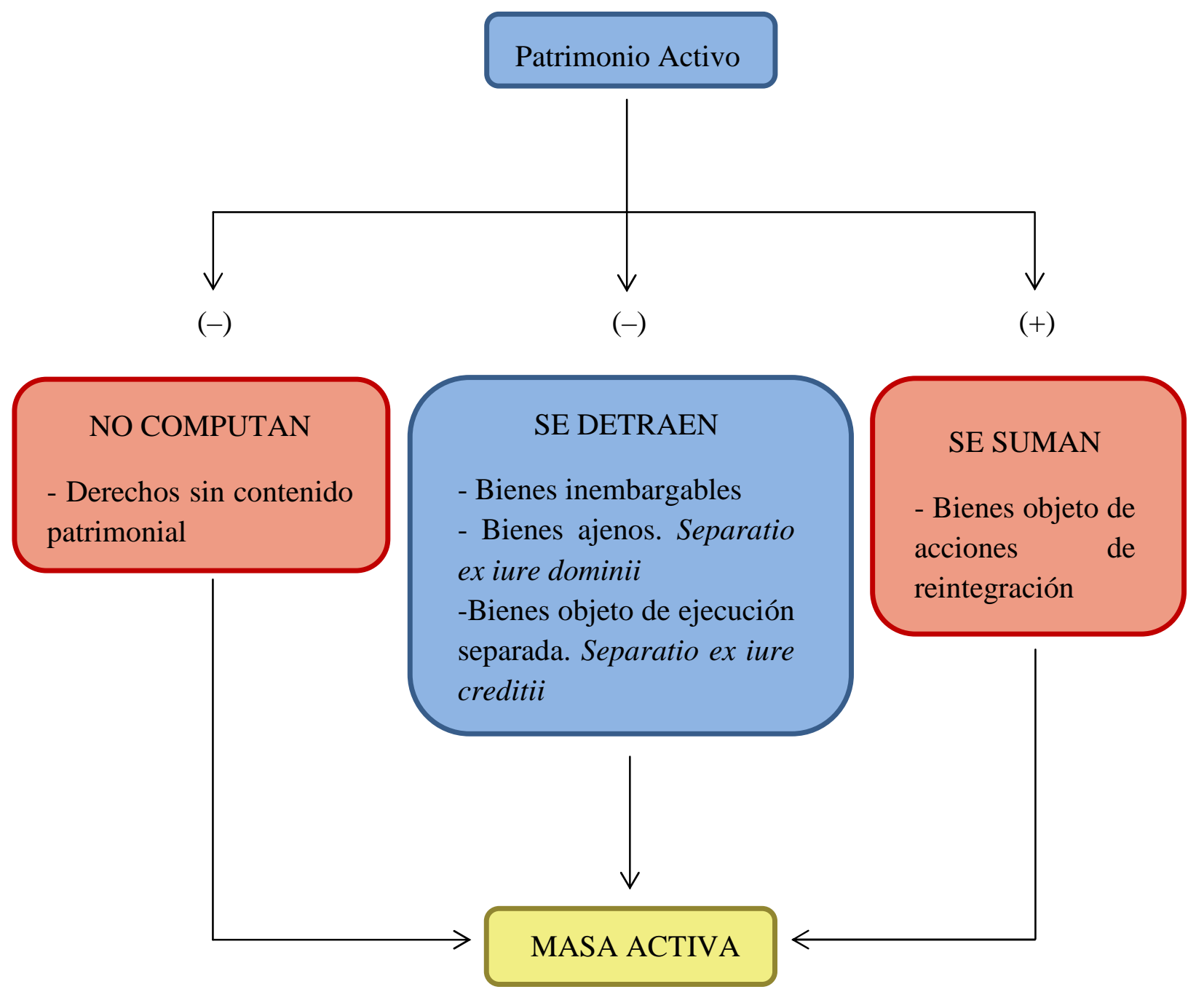

Elaboración propia

c) Conceptos que se restan al patrimonio activo

En primer lugar, me ocuparé de aquellos conceptos que obligatoriamente y en todo caso van a quedar fuera de la composición de la masa activa. En este apartado se debe mencionar, aunque estrictamente no formen parte del patrimonio activo, los derechos del deudor que carecen de contenido patrimonial. Se trata de aquellos derechos de la personalidad, cuyo carácter es indisponible y por tanto no pueden afectarse al pago de una deuda. Además, hay otros bienes o derechos que nunca vamos a contabilizar a la hora de determinar la masa activa, y que se diferencian de los anteriores en que éstos sí forman parte del patrimonio activo del concursado, se trata de los bienes inembargables. Están recogidos en los artículos 605 a 607 LEC: los bienes que hayan sido declarados 
inalienables; los derechos accesorios, que no sean alienables con independencia del principal; los bienes que carezcan, por sí solos, de contenido patrimonial; los bienes expresamente declarados inembargables por alguna disposición legal; el mobiliario y el menaje de la casa, así como las ropas del ejecutado y de su familia, en lo que no pueda considerarse superfluo, y en general, aquellos bienes como alimentos, combustible y otros que, a juicio del Tribunal, resulten imprescindibles para que el ejecutado y las personas de él dependientes puedan atender con razonable dignidad a su subsistencia; los libros e instrumentos necesarios para el ejercicio de la profesión, arte u oficio a que se dedique el ejecutado, cuando su valor no guarde proporción con la cuantía de la deuda reclamada; los bienes sacros y los dedicados al culto de las religiones legalmente registradas; las cantidades expresamente declaradas inembargables por Ley o Tratado Internacional ratificado por España; el salario, sueldo o pensión, en lo que no exceda los límites impuestos en el artículo 607 LEC.

En segundo lugar, tenemos que distinguir algunos bienes y derechos, que por regla general no formarán parte de la masa activa, sin embargo, dicha exclusión requiere que se interponga la correspondiente acción. Podemos diferenciar:

- Bienes ajenos. El titular legítimo de bienes que estén en poder del concursado cuenta con un derecho de separación sobre los mismos (separatio ex iure dominii). Esta facultad es reconocida en el artículo 80 LCon y para ejercitarla basta con una mera solicitud a la administración concursal. No procederá tal operación de separación cuando el deudor ostente sobre los bienes algún derecho de uso, garantía o retención. Respecto de la imposibilidad para llevar a cabo el derecho de separación, se pronuncia el artículo 81.1 LCon: "Si los bienes y derechos susceptibles de separación hubieran sido enajenados por el deudor antes de la declaración de concurso a tercero de quien no puedan reivindicarse, el titular perjudicado podrá optar entre exigir la cesión del derecho a recibir la contraprestación si todavía el adquirente no la hubiera realizado, o comunicar a la administración concursal, para su reconocimiento en el concurso, el crédito correspondiente al valor que tuvieran los bienes y derechos en el momento de la enajenación o en otro posterior, a elección del solicitante, más el interés legal".

- Bienes objeto de ejecución separada. El artículo 76.3 LCon recoge la llamada separatio ex iure creditii, tradicionalmente se ha concebido como un derecho de 
separación que no tiene como causa la propiedad de ajena sino un mejor derecho ostentado por un tercero ${ }^{8}$. Actualmente, -y de manera acertada- son muchos los autores que determinan que la afección de ciertos bienes al pago de determinadas deudas no comporta un derecho de separación en sí, sino a una simple ejecución singular permitida por la Ley ${ }^{9}$. El artículo 76.3, recoge tal institución, pero únicamente en relación con los titulares de créditos con privilegios sobre buques y aeronaves. Siguiendo a RODRÍGUEZ DE QUIÑONES Y DE TORRES ${ }^{10}$, más que un caso de separación, estaríamos hablando de ejecución separada en cuanto a algunos bienes que cuentan con un privilegio tal, que los hace desaparecer de la esfera concursal. Fuera de la Ley Concursal, existen otros supuestos similares referidos a las sociedades de sistemas, mercados secundarios oficiales de futuros y opciones, sistemas de compensación y liquidación de valores o instrumentos financieros derivados, garantías constituidas en favor de Bancos Centrales, etc.

d) Conceptos que se suman al patrimonio activo

Para el cómputo de la masa activa, se han de sumar al patrimonio activo del concursado aquellos bienes que salieron de éste con anterioridad a la declaración de concurso, pero que vuelven a formar parte de la esfera económica del deudor en virtud de acciones de reintegración. En la legislación anterior a 2003, existía un mecanismo similar al que aquí se va a exponer, de hecho, los objetivos que persiguen son idénticos, sin embargo difiere la forma de llevarlos a cabo. El tratamiento de la cuestión fue una de las mayores novedades de la regulación vigente, que venía a sustituir un sistema que creaba gran inseguridad jurídica al prever la nulidad automática de todos los actos de disposición y administración del quebrado llevados a cabo durante el periodo de

\footnotetext{
${ }^{8}$ PRENDES CARRIL, P., ALVARGONZÁLEZ TREMOLS, A., y GÓMEZ MARTíN, F., Guía Práctica Concursal (dirigido por PRENDES CARRIL, P.), Pamplona, Aranzadi, 2008, pág. 142.

${ }^{9}$ Por todos, CORDÓn MORENO, F., Proceso... op. cit., pág. 191.

${ }^{10}$ RODRÍGUEZ DE QUIÑONES Y DE TORRES, A., "La determinación de las masas activa y pasiva del concurso", Derecho Mercantil II (Coordinado por JIMÉNEZ SÁNCHEZ, G.) Madrid, Marcial Pons, 2010, págs. 952 y ss.
} 
retroacción ${ }^{11}$. La inseguridad se hacía mayor ya que los síndicos de la quiebra no siempre ejercían la acción de nulidad. El resultado era la confusión absoluta en torno al estatus de los actos de disposición realizados por el deudor con anterioridad a la declaración de quiebra.

La nulidad automática durante un periodo de retroacción fue sustituida en la Ley $22 / 2003$ por las acciones de reintegración. Se trata de una posibilidad rescisoria ${ }^{12}$ respecto de ciertos actos, que han de cumplir una serie de condiciones (art. 71.1 LCon): en primer lugar, el elemento temporal es básico, puesto que solo cabrá rescisión respecto de actos realizados dentro de los dos años anteriores a la declaración de concurso; en segundo lugar, tendrá que referirse la acción de reintegración a actos que supusieron un perjuicio efectivo a la masa activa. De manera que quien ejercita la acción deberá probar el perjuicio aludido, sin que tal carga probatoria deba alcanzar la intención fraudulenta del deudor ${ }^{13}$. Aquí podemos diferenciar la reintegración, de la acción del artículo 40.7 LCon, que como se ha visto anteriormente, y como señala la jurisprudencia distinguiéndola de la posibilidad rescisoria que se está caracterizando, precisa (la acción del art. 40.7 LCon) que los actos de disposición hayan sido realizados con posterioridad a la declaración de concurso y que lo hayan sido sin la autorización de la administración concursal ${ }^{14}$.

Para probar el perjuicio patrimonial, el extenso artículo 71 LCon establece un orden de presunciones, que determinarán la actuación probatoria del solicitante de la rescisión en función del tipo de acto que se trate. La inclusión de los acuerdos de refinanciación entre los actos no susceptibles de rescisión, ha tenido lugar con el Real

\footnotetext{
${ }^{11}$ PIÑEL LÓPEZ, E., "Efectos del concurso sobre los acreedores, los créditos, los contratos y los actos perjudiciales para la masa", Revista de Derecho Concursal y Paraconcursal. Anales de Doctrina, Praxis, Jurisprudencia y Legislación, La Ley, nº 2, 2005, pág. 48.

${ }^{12}$ Sobre el término rescisión aplicado a esta cuestión, señalando las dificultades que podrían darse en torno al encaje de la figura que se caracteriza con los esquemas civiles de la rescisión clásica, pero determinando finalmente la pertinencia del término dadas sus similitudes, GIL RODRÍGUEZ, J., Comentarios a la Ley Concursal (coordinado por BERCOVITZ RODRÍGUEZ-CANO, R.), Volumen I, Madrid, Tecnos, 2004, págs. 841 y ss.

${ }^{13}$ PIÑEL LÓPEZ, E., “Efectos...” op. cit., pág. 48.

${ }^{14}$ Sentencia de la Audiencia Provincial de Barcelona (Sección 15), 2/2010, de 13 de enero, F. D. $3^{\circ}$.
} 
Decreto 3/2009 y la Ley 38/2011, que han modificado la LCon. Su entrada en esta lista, está condicionada a que el acuerdo cumpla ciertas condiciones que se explicitan en la propia Ley Concursal y que no se repetirán aquí, pues la sustancia se encuentra no en los requisitos que se imponen al acuerdo, sino en la concepción del mismo como un acto que en principio no puede ser contrario a la masa ${ }^{15}$, además de otorgarse así seguridad en la inversión del re-financiador.

Los efectos básicos de la acción (siempre que sea estimada), se concretan en la ineficacia del acto impugnado y en la restitución de las prestaciones objeto de éste, con sus frutos e intereses. Por otro lado, la legitimación para instarla en principio corre a cargo de la administración concursal, sin embargo "los acreedores que hayan instado por escrito de la administración concursal el ejercicio de alguna acción, señalando el acto concreto que se trate de rescindir o impugnar y el fundamento para ello, estarán legitimados para ejercitarla si la administración concursal no lo hiciere dentro de los dos meses siguientes al requerimiento" (art. 72.1 LCon). A pesar de esta previsión, la Ley 38/2011 ha introducido una salvedad en esta materia, estableciendo que tal legitimación subsidiaria no tendrá lugar, es decir, que la administración concursal será el único legitimado para instar las acciones rescisorias o impugnatorias respecto de acuerdos de refinanciación ${ }^{16}$ (cuando sea posible hacerlo, teniendo en cuenta que si se cumplen las condiciones establecidas por la LCon tales negocios jurídicos no pueden ser rescindidos).

e) Supuestos especiales

A excepción de los depósitos irregulares de dinero, el resto son recogidos de forma expresa en la Ley Concursal por resultar dudosa su naturaleza o problemática su inclusión en la masa activa del concurso:

- Depósitos irregulares de dinero. Se da un caso realmente peculiar, el del concursado depositario en relación a un depósito de dinero, esto es, irregular por tratarse

\footnotetext{
${ }^{15}$ Tal característica le otorga CANDELARIO MACÍAS, Mª I., Lecciones de Derecho concursal, Madrid, Tecnos, 2012, pág. 91.

${ }^{16}$ Artículo 72.2 LCon.
} 
de un bien fungible ${ }^{17}$. El depósito supone la transmisión del dominio, quedándose el depositante a partir de dicho momento, con un derecho de crédito, consistente en la restitución de bienes del mismo género, calidad y cantidad. Dicha transmisión del dominio ha llevado a la doctrina a negar el derecho de separación, lo que tiene gran relevancia cuando se trata de retenciones en favor de la Hacienda Pública, Seguridad Social, o el resto de Administraciones Públicas.

- Bienes conyugales. En el concurso de persona casada, los bienes privativos del cónyuge concursado por supuesto entran a formar parte de la masa activa. Pero además, si el régimen económico-matrimonial es la sociedad de gananciales, los bienes gananciales o comunes cuando deban responder de obligaciones del concursado, también se integrarán en la masa activa. Por otro lado, en el régimen económico de separación de bienes, la LCon ha mantenido una tradicional prescripción de nuestro Derecho, la presunción muciana ${ }^{18}$, que supone en beneficio de la masa (iuris tantum), que el concursado "donó a su cónyuge la contraprestación satisfecha por éste para la adquisición de bienes a título oneroso cuando esta contraprestación proceda del patrimonio del concursado" (art. 78.1 LCon). Además, cuando no pueda probarse dicha procedencia se presumirá, salvo prueba en contrario, que la mitad de ella fue donada por el concursado a su cónyuge (siempre que la adquisición de los bienes se haya realizado en el año anterior a la declaración de concurso).

- Bienes en comunidad y cuentas indistintas. La regla general, que lleva a considerar que los bienes y derechos que pertenecen a varios en comunidad integran la masa activa solo en la cuota que corresponda al concursado, presumiéndose la igualdad en las porciones de tal comunidad (art. 393 CC), tiene una importante excepción en la Ley 22/2003. El artículo 79 LCon dispone que, salvo prueba en contrario, los saldos acreedores de cuentas en las que el concursado figure como titular indistinto se integrarán en la masa activa. Se trata de una excesiva presunción de propiedad total de

\footnotetext{
17 AAVV., Sociedades Mercantiles. Memento práctico, Madrid, -coordinado y editado por- Ediciones Francis Lefebvre, 2010, pág. 1265.

${ }^{18}$ Que se recogía en el artículo 1442 CC, y de la que se ocupa ampliamente FRADEJAS RUEDA, O. M., "Un anacronismo en la modernización de nuestro Derecho concursal: la presunción muciana del artículo 78.1 de la Ley Concursal", Estudios sobre la Ley Concursal. Libro homenaje a Manuel Olivencia, Tomo IV, Madrid, Marcial Pons, 2004, págs. 4045 y ss.
} 
los saldos acreedores de cuentas indistintas ${ }^{19}$, que no está exenta de polémica, pues la norma impone una carga muy importante a los cotitulares indistintos si quieren salvar su patrimonio, la de probar que los saldos en cuestión no pertenecen al concursado.

- Bienes adquiridos con pacto de sobrevivencia. Prescribe el artículo 78.3 LCon: "Los bienes adquiridos por ambos cónyuges con pacto de sobrevivencia se considerarán divisibles en el concurso de cualquiera de ellos, integrándose en la masa activa la mitad correspondiente al concursado". Sin embargo, se reconoce al cónyuge del concursado un derecho de adquisición del bien, que se puede ejercitar mediante la aportación de dicha cantidad a la masa ${ }^{20}$.

\section{f) Referencia al inventario}

Pues bien, siguiendo estas reglas, y otras contenidas en el artículo 82 LCon, la administración concursal deberá realizar un inventario de la masa activa del deudor. Se trata de una operación de suma importancia pues, como se ha podido comprobar, de la inclusión de unos bienes y derechos u otros en la masa activa, dependerá directamente la satisfacción de los acreedores, ya que entendemos dicha masa como un patrimonio de ejecución. La puesta en práctica de tales normas que perfilan la masa activa, tienden a conseguir la identidad entre dos conceptos que puso de relieve el profesor GARRIGUES $^{21}$, la masa de hecho (la que hay en el momento de la declaración de concurso) y la masa de Derecho (la que debe haber); su necesaria convergencia redunda en un Derecho concursal más justo.

De cada uno de los bienes y derechos relacionados en el inventario se expresará su naturaleza, características, lugar en que se encuentre y, en su caso, datos de identificación registral. Se indicarán también los gravámenes, trabas y cargas que afecten a estos bienes y derechos, con expresión de su naturaleza y los datos de

\footnotetext{
${ }^{19}$ PRENDES CARRIL, P., ALVARGONZÁleZ TREMOLS, A., y GÓMEZ MARTín, F., Guía... op. cit., pág. 149.

${ }^{20}$ AAVV., Sociedades Mercantiles. Memento práctico, Madrid, -coordinado y editado por- Ediciones Francis Lefebvre, 2010, pág. 1263.

${ }^{21}$ GARRIGUES, J., Curso de derecho mercantil, Tomo II, Madrid, Aguirre, 1940, pág. 482 (citado por CORDÓN MORENO, F., Proceso concursal, Pamplona, Aranzadi, 2013, pág. 192).
} 
identificación. Este inventario debe realizarse a la mayor brevedad posible y siempre dentro del plazo establecido para la emisión del informe. Además de las circunstancias señaladas, se hará constar en una relación, todos los litigios que puedan afectar al inventario y en otra, las acciones que la propia administración concursal estime necesarias para la reintegración de bienes en la masa activa. Por otro lado, el artículo 83 LCon reconoce la posibilidad de la administración concursal de recurrir a expertos independientes en busca de asesoramiento para la formación del inventario de la masa activa.

\section{DETERMINACIÓN DE LA MASA PASIVA}

La masa pasiva del concurso queda definida en el artículo 84.1 LCon como la suma de "los créditos contra el deudor común que conforme a esta Ley no tengan la consideración de créditos contra la masa". Sin embargo, podemos encontrar delimitaciones más didácticas del concepto (y que no aluden a los créditos contra la masa, a los que más tarde se dedica un epígrafe) en la doctrina. BROSETA PONT y MARTÍNEZ SANZ, definen la masa pasiva señalando que declarado el concurso, las acciones individuales de los acreedores quedan paralizadas y éstos quedan agrupados en un consorcio de interesados en la ejecución del patrimonio del quebrado ${ }^{22}$.

En lo que sigue, se van a presentar los aspectos más fundamentales sobre la composición de la masa pasiva del concurso. A este respecto, es básico conocer los diferentes tipos de créditos que la integran y el orden de prelación en el cobro de los mismos. La clasificación de los créditos es una parte fundamental del concurso, de hecho, desde el punto de vista del acreedor será el momento crítico del procedimiento, donde puede hacerse una idea de las posibilidades que tiene de satisfacer su derecho de crédito.

\footnotetext{
${ }^{22}$ BROSETA PONT, M. y MARTÍNEZ SANZ, F., Manual de Derecho mercantil, Volumen II, Madrid, Tecnos, 2012, pág. 615.
} 
Las reglas que ordenan esta parte del concurso van a determinar el afloramiento de estrategias que llevarán a cabo los acreedores ${ }^{23}$, con el objetivo de privilegiar sus créditos para que les sea más fácil cobrar lo que les corresponde cuando se llegue (si se llega) a la liquidación. Siendo conscientes de esta importancia, no podemos negar que debemos estar acercándonos al sentido de la institución concursal con el estudio de las categorías en que se insertan las deudas del concursado, en concreto, en la búsqueda del fundamento jurídico de tal expresión normativa.

\section{Comunicación y reconocimiento de créditos}

Pese a que el pago de los créditos del concursado no tiene lugar hasta que se abre fase de liquidación o convenio (solución del concurso), han de ser comunicados a la administración concursal por sus acreedores en el plazo de un mes desde que se publica en el Boletín Oficial del Estado el auto declarativo de concurso. Se trata de un trámite necesario para que el órgano de administración del procedimiento realice de forma efectiva la integración de la masa pasiva, incluyendo a los acreedores en la lista habilitada a tal efecto (reconocimiento).

La LCon señala en su artículo 86.2, algunos créditos que de forma obligatoria deberán ser reconocidos por la administración concursal: aquellos que obran en libros, documentos del concursado, los reconocidos por laudo arbitral, certificación administrativa o documento ejecutivo, los asegurados con garantía real inscrita en registro público y los créditos de los trabajadores que resulten de los libros del deudor (éstos ni siquiera tienen que ser comunicados, su reconocimiento es automático). La legislación concursal ha querido determinar las condiciones de la irrupción de ciertos créditos en la masa pasiva del concurso, puesto que la operación de reconocimiento se complica en algunos supuestos concretos (art. 87 LCon):

- Créditos condicionales. La Ley define únicamente como condicionales, aquellos sometidos a condición resolutoria, otorgando otra denominación (créditos

\footnotetext{
${ }^{23}$ VICENT CHULIÁ, F., Introducción al Derecho mercantil, Volumen II, Valencia, Tirant lo Blanch, 2012, pág. 2129.
} 
contingentes) a los que están sometidos a condición suspensiva. Los primeros son reconocidos -como créditos condicionales-, siguiéndose el mismo proceso que para el resto de deudas. No obstante, si se cumple la condición o se estima el recurso, éstos pierden su condición de créditos concursales ${ }^{24}$. Este régimen jurídico será extensible a los créditos de Derecho público de la Administración, recurridos en vía administrativa o jurisdiccional.

- Créditos contingentes. Son los que están sometidos a condición suspensiva y los litigiosos. La posición del titular del crédito sometido a condición suspensiva es sustancialmente mejor en el ámbito concursal que en el orden civil. En este último tan solo cuenta con ciertas acciones tendentes a la conservación de su expectante derecho. Sin embargo, la LCon le reconoce su crédito, admitiéndolo como acreedor concursal ${ }^{25}$. Este reconocimiento tiene lugar sin cuantía propia y limitándose algunas facultades propias del acreedor, como los derechos de adhesión, voto y cobro. Tal tratamiento se dará también a los créditos de Derecho público de las Administraciones Públicas, que resulten de procedimientos de comprobación o inspección (hasta su cuantificación).

- Créditos con avalista, fiador u obligado solidario ${ }^{26}$. Son aquellos en que existe garantía de pago por un tercero no concursado, ya sea en concepto de aval, fianza u obligación solidaria. Estos créditos se reconocen sin limitación, de manera que si el avalista, fiador u obligado solidario paga al acreedor, cambiará la titularidad del crédito concursal. En caso de que el avalista haya satisfecho la deuda de manera parcial con anterioridad a la declaración de concurso, la LCon establece un sistema discriminatorio para este último, pues por razones de orden y economía procesal del concurso, será el propio acreedor principal quien obtenga la satisfacción de la totalidad del crédito,

\footnotetext{
${ }^{24}$ RODRÍGUEZ DE QUIÑONES Y DE TORRES, A., “La determinación...”op. cit., págs. 960-961.

25 ROCA GUILLAMÓN, J. "Las expectativas en el concurso de acreedores", Los acreedores concursales. II Congreso Español de Derecho de la Insolvencia (dirigido por ROJO, A. y BELTRÁN, E.), Pamplona, Aranzadi, 2010, pág. 83.

${ }^{26}$ Es necesario señalar que aquí se ha seguido la posición doctrinal que trata conjuntamente los artículos 87.6 y 86.7 LCon, entendiendo que pese a no utilizar exactamente la misma terminología ("acreedor que disfrute de fianza de tercero" y "crédito con avalista, fiador u obligado solidario" respectivamente) se están refiriendo a una misma realidad, los créditos garantizados por un tercero de manera personal. En este sentido, RODRÍGUEZ DE QUIÑONES Y DE TORRES, A., “La determinación...” op. cit., pág. 961.
} 
incluidas las cantidades que han sido pagadas por el tercero no concursado, que deberá repetir contra el acreedor tras la conclusión del concurso, para poder obtener el montante que le corresponde.

\section{Crédito contra la masa y crédito concursal}

El régimen de comunicación y reconocimiento que se acaba de esbozar no se va a dar en todos los casos, existen créditos que al escapar de su integración en la masa pasiva, se desligan también de tales requisitos formales. Estamos refiriéndonos a los créditos contra la masa, una categoría con tradición en el Derecho concursal y que implica que determinados acreedores van a quedar fuera de ese consorcio de interesados en el patrimonio del concursado que es la masa pasiva. En la Ley 22/2003 no se deja tan claro como podría esperarse que los créditos contra la masa se exceptúan del régimen de comunicación y reconocimiento de $\operatorname{créditos}^{27}$, sin embargo, es meridiana la intención del legislador de establecer esta categoría, segregando las deudas así calificadas, del resto de créditos. Hasta tal punto es clara la distinción que, mientras lo relativo a la determinación de la masa pasiva del concurso y a la comunicación, reconocimiento, graduación y clasificación de los créditos concursales integra la sección cuarta del juicio de concurso (art. 183-4. ${ }^{\circ}$ ), los créditos contra la masa - "las deudas de la masa”integran la sección tercera (art. 183-3. ${ }^{\circ}$ in fine $)^{28}$.

Las diferencias entre el crédito contra la masa y el crédito concursal (aquel que se integra en la masa pasiva) son fundamentales. Los primeros tienen la consideración de prededucibles, en el sentido de que han de ser satisfechos con cargo a la masa activa

\footnotetext{
${ }^{27}$ No obstante, no puede dudarse que existe tal excepción: el hecho de que los créditos contra la masa no deban ser comunicados, sino reclamados a la administración concursal, no se contradice con el hecho de que deban ser relacionados en una lista por la propia administración concursal (normalmente como documento anexo a la lista de acreedores que acompaña a su informe). MEANA PASCUAL, D., "La comunicación tardía de créditos en el concurso de acreedores", Noticias jurídicas. Artículos Doctrinales: Derecho Mercantil, noviembre de 2011.

${ }^{28}$ BELTRÁN, E., "Créditos concursales y créditos contra la masa”, Estudios de Derecho Judicial, no 59, 2004, pág. 443.
} 
del concurso con carácter previo al pago de los restantes créditos (concursales) ${ }^{29}$. Dada esta característica de absoluta (en principio) prelación a la hora del cobro, debemos recuperar aquí el artículo 84.2 LCon que recoge qué deudas serán calificadas de esta forma:

$1^{\circ}$. Los créditos por salarios por los últimos treinta días de trabajo efectivo anteriores a la declaración de concurso y en cuantía que no supere el doble del salario mínimo interprofesional.

$2^{\circ}$. Las costas y gastos judiciales necesarios para la correcta tramitación del procedimiento y sus incidentes.

$3^{\circ}$. Las costas y gastos judiciales ocasionados por la asistencia y representación del deudor, de la administración concursal o de acreedores legitimados en los juicios que, en interés de la masa, continúen o inicien conforme a lo dispuesto en la Ley.

$4^{\circ}$. Los créditos por alimentos del deudor y de las personas respecto de las cuales tuviera el deber legal de prestarlos, conforme a lo dispuesto en la LCon; así como los alimentos a cargo del concursado acordados por el Juez de Primera Instancia en alguno de los procesos a que se refiere el Título I del Libro IV de la Ley de Enjuiciamiento Civil.

$5^{\circ}$. Las deudas generadas por el ejercicio de la actividad profesional o empresarial del deudor tras la declaración del concurso, incluyendo los créditos laborales, comprendidas en ellos las indemnizaciones de despido o extinción de los contratos de trabajo, así como los recargos sobre las prestaciones por incumplimiento de las obligaciones en materia de salud laboral.

$6^{\circ}$. Los créditos que resulten de prestaciones a cargo del concursado en los contratos con obligaciones recíprocas pendientes de cumplimiento que continúen en vigor tras la declaración de concurso, y de obligaciones de restitución e indemnización en caso de resolución voluntaria o por incumplimiento del concursado.

\footnotetext{
29 TATO PLAZA, A., "Reconocimiento y graduación de créditos en la nueva ley concursal”, Revista Xurídica Galega, No 40, 2003, págs. 39-40.
} 
$7^{\circ}$. Los que, en los casos de pago de créditos con privilegio especial sin realización de los bienes o derechos afectos, en los de rehabilitación de contratos o de enervación de desahucio y en los demás previstos en esta Ley, correspondan por las cantidades debidas y las de vencimiento futuro a cargo del concursado.

$8^{\circ}$. Las deudas que derivando de la rescisión concursal de actos realizados por el deudor, correspondan a la devolución de contraprestaciones recibidas por éste, salvo que la sentencia apreciare mala fe en el titular de este crédito.

$9^{\circ}$. Las cantidades que resulten de obligaciones válidamente contraídas durante el procedimiento por la administración concursal o, con la autorización o conformidad de ésta, por el concursado sometido a intervención.

$10^{\circ}$. Los créditos por de obligaciones nacidas de la Ley o de responsabilidad extracontractual del concursado con posterioridad a la declaración de concurso.

$11^{\circ}$. El cincuenta por ciento de los créditos que supongan nuevos ingresos de tesorería y hayan sido concedidos en el marco de un acuerdo de refinanciación. En caso de liquidación, los créditos concedidos al concursado en el marco de un convenio (no se aplica a ingresos realizados por el propio deudor o personas relacionadas a través de operaciones como préstamos o aumentos de capital).

$12^{\circ}$. Cualesquiera otros créditos a los que la Ley atribuya expresamente tal consideración.

Esta enumeración que hace la Ley Concursal, se vale del sistema de numerus apertus, de manera que los créditos contra la masa no aparecen únicamente en el artículo 84.2 LCon, sino que pueden estar desperdigados por todo el texto. Con independencia de ese dato, hay que tratar de encontrar la justificación a esta diferenciación crediticia, para entender qué es lo que se pretende con los créditos contra la masa. Algunos autores se ocupan de la cuestión señalando que estos créditos responden a obligaciones contraídas con posterioridad a la declaración de concurso ${ }^{30}, \mathrm{y}$ no se equivocan, aunque los nuevos perfiles del Derecho concursal han hecho matizar (más de lo debido) esta circunstancia.

\footnotetext{
${ }^{30}$ Por todos, VICENT CHULIÁ, F., Introducción... op. cit., pág. 2120.
} 
El profesor BELTRÁN ${ }^{31}$ discurre sobre el problema de la justificación de los créditos contra la masa, pudiendo inferirse de su acertado análisis, cuatro interesantes conclusiones:

Los créditos contra la masa se conciben como el coste del concurso, se trata de deudas que adquiere el deudor (y no la masa activa que no tiene esa capacidad) como consecuencia del procedimiento concursal, o tras la declaración de éste. Así las cosas, se entiende que en la enumeración anterior entren las costas judiciales y créditos similares. En ellos se manifiestan los costes del procedimiento, o aquellos que son fruto de obligaciones nacidas durante éste. En definitiva, se pueden entender como créditos que han nacido tras la declaración de concurso; a diferencia de los concursales, que son los que lo han provocado.

En segundo lugar, la justificación a esta prioridad de los créditos contra la masa, pasa porque es necesario otorgar cierta seguridad a las obligaciones que surgen con posterioridad a la declaración de concurso ya que de otro modo sería imposible encontrar un tercero que concediera financiación al concursado. Por tanto debemos atender a la función de estos créditos y a su naturaleza extraconcursal para entender su prioridad en el cobro.

En tercer lugar, la concepción de los créditos contra la masa en los términos aquí expuestos, esto es, como aquellos gastos propios del concurso y obligaciones surgidas tras el mismo, está en crisis. Ambos requisitos, el teleológico (costes necesarios para hacer posible el procedimiento) y el temporal (obligaciones posteriores a la declaración), que se exigen en principio a los créditos contra la masa, se han visto vilipendiados por el legislador. Esta tesis encuentra su razón de ser en la inclusión de conceptos en el artículo 84.2 LCon como "los créditos por salarios por los últimos treinta días de trabajo efectivo anteriores a la declaración de concurso". En este caso se ha utilizado el crédito contra la masa como una suerte de superprivilegio, desdibujando la figura inicial, que no se circunscribía a cuestiones de prelación en el pago de las deudas sino a un criterio de pura extraconcursalidad.

\footnotetext{
${ }^{31}$ BELTRÁN, E., "La prioridad de los créditos contra la masa”, Estudios sobre la Ley Concursal. Libro homenaje a Manuel Olivencia, Tomo IV, Madrid, Marcial Pons, 2004, págs. 3611 y ss.
} 
Por último, los titulares de créditos contra la masa guardan cierta tensión entre sí y no solo con respecto a los acreedores concursales (obvia por la prededucibilidad de los primeros). Esta tensión se manifiesta en los casos en que la masa activa no es suficiente para hacer frente a los créditos contra la masa (fracaso absoluto del procedimiento, que no es capaz de hacer frente a su propio coste). Aquí resultan aplicables las reglas del artículo 84.3 LCon, siendo el criterio general para llevar a cabo el pago de los créditos contra la masa, el de sus "respectivos vencimientos" 32 . Los acreedores contra la masa insatisfechos, una vez concluido el concurso tienen diferentes opciones, como exigir responsabilidad a la administración concursal por desatender el pago de sus créditos en prededucción (o asumirlos conociendo la insuficiencia de la masa activa para hacerles frente); repetir contra los acreedores concursales por créditos satisfechos indebidamente; o actuar contra el deudor ejercitando su derecho. Este último no prescribe con la finalización del procedimiento, pero pierde la prioridad ya que el mecanismo de prededucibilidad es propio de la institución concursal y sí termina con el fin del proceso.

\section{Clasificación de los créditos concursales}

Conviviendo con los créditos contra la masa, se encuentran las deudas que sí van a integrarse en la masa pasiva del concurso. Se trata de aquellas que preexistían a la declaración judicial que inicia el procedimiento, y que son causa de éste. Los titulares de estos derechos serán incluidos además en la lista de acreedores que realiza la administración concursal, y estarán sujetos a las reglas de comunicación y reconocimiento de créditos, y en general al resto de disposiciones de la LCon. Podemos encontrar créditos concursales de cuatro tipos: subordinados, con privilegio especial, con privilegio general y ordinarios. Cada uno de ellos ocupa un lugar distinto en el orden de prelación de pagos, de manera que comenzaremos por los que se satisfacen en primer lugar, e iremos bajando hasta los que se liquidan en último lugar.

\footnotetext{
${ }^{32}$ No obstante, no podrán iniciarse ejecuciones judiciales o administrativas para hacerlos efectivos hasta que se apruebe el convenio, se abra la liquidación o transcurra un año desde la declaración de concurso sin que se hubiere producido ninguno de estos actos. Las acciones relativas a la calificación o al pago de estos créditos se ejercitarán ante el Juez del concurso por los trámites del incidente concursal.
} 
- Créditos con privilegio especial. Son los que satisfacen en primer término. Su realización se lleva a cabo con cargo a los bienes y derechos que están afectos a los mismos, pues se trata de créditos con algún tipo de garantía sobre determinados activos del concursado. Se trata de los créditos que aparecen en el artículo 90 LCon: garantizados con hipoteca, prenda ${ }^{33}$, anticresis, garantía de valores mediante anotación en cuenta, créditos refaccionarios sobre bienes refaccionados (incluidos los de los trabajadores sobre los objetos por ellos elaborados mientras estén en posesión del concursado) y las cuotas de arrendamiento financiero o plazos de compraventa con precio aplazado.

Las reglas que rigen el pago de éstos créditos se encuentran en el artículo 155 LCon, destacando dos: normalmente, la realización de los bienes y derechos afectos a créditos con privilegio especial se hará por medio de subasta; y si un mismo bien o derecho se encontrase afecto a más de un crédito con privilegio especial, los pagos se realizarán conforme a prioridad temporal. No obstante, lo que resulta ciertamente sorprendente es que el respeto a los bienes y derechos que garantizan créditos con privilegio especial alcanza no solo al resto de créditos concursales ${ }^{34}$, sino también a los propios créditos contra la masa. El artículo 154 LCon en su párrafo segundo recoge esta prescripción. Aquí no es en absoluto extraño dudar sobre la veracidad de lo expuesto, o sobre la congruencia de la Ley, que consagra un tipo de créditos (contra la masa) como extraconcursales y con una prioridad absoluta, cuando en realidad éstos deben respetar la satisfacción de ciertos créditos concursales: los que tienen privilegio especial.

Pero no es la única incongruencia del ordenamiento concursal a este respecto. $\mathrm{Si}$ nos remontamos al cómputo de la masa activa, podemos traer a colación una figura que guarda en mi opinión identidad con los créditos con privilegio especial, la denominada separatio ex iure creditii. Cuando la caracterizábamos, nos referíamos a ella como una ejecución separada sobre buques y aeronaves (ya que no se comparte la configuración de ésta como un derecho de separación para el acreedor). Pues bien, esto es básicamente un crédito con privilegio especial, siendo la nota distintiva de unos y otros la afectación

\footnotetext{
${ }^{33}$ Constituida en documento público y cumpliendo el resto de condiciones del artículo 91 LCon.

${ }^{34}$ Sobre los que se sitúan los especialmente privilegiados en este esquema de satisfacción de deudas.
} 
de la deuda a un bien concreto. Este bien no podrá ser enajenado por la administración concursal, puesto que la garantía que encarna le otorga un segundo nivel de intangibilidad. A los efectos que nos interesan, no debemos reparar en si el crédito se incluye en la masa concursal (crédito con privilegio especial) o no (derecho de ejecución separada). La separatio ex iure creditii solo se reconocía respecto de buques y aeronaves, no obstante, los consecuencias de la calificación de un crédito como privilegiado especial (en relación a otros tipos de bienes), son sustancialmente idénticas. En mi opinión, estamos tratando con dos casos de ejecución separada de créditos por la afección de un bien que los garantiza y que la LCon protege especialmente.

Sin embargo, existe un caso en que esta intangibilidad puede ceder en beneficio de los créditos contra la masa (art. 155.3 LCon). Este fenómeno se concreta en la opción de la administración concursal, de (mediando autorización judicial) conseguir la liquidez suficiente para el pago de créditos contra la masa procediendo a la enajenación de bienes afectos a créditos con privilegio especial, siempre que respete la regla de preferencia en la satisfacción de los titulares de dichos créditos. El presupuesto será, evidentemente, que el valor del bien supere al del crédito privilegiado $^{35}$. Por tanto, pueden mantenerse las dudas sobre la prelación de créditos en el concurso: se proclama la superioridad de los créditos contra la masa, que escapan a la cuantificación concursal, pero al mismo tiempo éstos quedan supeditados al escrupuloso respeto del valor de los créditos calificados con privilegio especial.

- Créditos con privilegio general. La caracterización de éstos se encuentra en el artículo 91 LCon, mientras que la forma de satisfacerlos está en el artículo 156 LCon. Su aplicación no resulta tan problemática como en anteriores casos. Podríamos situarlos en un tercer escalón, de manera que se satisfacen tras los créditos contra la masa y los especialmente privilegiados.

Dentro de los créditos con privilegio general, existe un orden concreto para organizar el pago de los mismos (a diferencia de los créditos contra la masa que se satisfacen con el criterio del vencimiento). Esta categoría se refiere a -por orden-: deudas por salarios que no estén cubiertas por el privilegio especial y hasta un límite

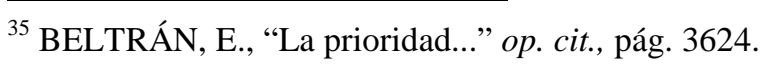


cuantitativo, indemnizaciones derivadas de la extinción de contratos, indemnizaciones por accidentes laborales; cantidades correspondientes a retenciones de seguridad social y tributarias que deban ser abonados por el concursado; créditos de personas naturales derivados del trabajo personal no dependiente y los que correspondan al propio autor por la cesión de los derechos de explotación de la obra objeto de propiedad intelectual; créditos tributarios y demás de Derecho público; créditos por responsabilidad civil extracontractual; créditos que supongan nuevos ingresos de tesorería en el marco de acuerdos de refinanciación (en la cuantía que no se reconozca como crédito contra la masa); y los créditos de los que es acreedor aquel que insta el concurso siempre que no pueda calificarse su crédito como subordinado hasta un 50\% de su importe.

- Créditos ordinarios. La definición de éstos se hace por exclusión: "se entenderán clasificados como créditos ordinarios aquellos que no se encuentren calificados en esta Ley como privilegiados ni como subordinados" (art. 89.3 LCon). Son el cuarto escalón de este esquema, su pago se efectuará una vez se hayan satisfechos los créditos contra la masa y los privilegiados.

- Créditos subordinados. Son el último peldaño dentro de la ordenación de deudas concursales. El pago de los créditos subordinados no se realizará hasta que hayan quedado íntegramente satisfechos los créditos ordinarios y se efectuará por el orden establecido en el artículo 92 LCon y, en su caso, a prorrata dentro de cada número (art. 158 LCon).

El mencionado artículo 92 señala los créditos que son subordinados, eliminándose toda posibilidad de discrecionalidad judicial ${ }^{36}$. Serán calificados como tal: los que, habiendo sido comunicados tardíamente, sean incluidos por la administración concursal en la lista de acreedores ${ }^{37}$; los que tengan el carácter de subordinados en virtud de un pacto contractual; recargos e intereses (a excepción de los créditos con garantía real); multas y sanciones similares; créditos cuyo acreedor es una persona

\footnotetext{
${ }^{36}$ BROSETA PONT, M. y MARTÍNEZ SANZ, F., Manual... op. cit., pág. 625.

37 Con esta previsión el legislador trata de fomentar la actitud despierta y diligente del acreedor, castigando la falta de cuidado o la impericia del mismo a la hora de comunicar sus derechos de crédito. FERRÉ FALCÓN, J., Los créditos subordinados, Pamplona, Aranzadi, 2006, pág. 171.
} 
especialmente relacionada con el deudor ${ }^{38}$; los créditos que como consecuencia de rescisión concursal resulten a favor de quien en la sentencia haya sido declarado parte de mala fe en el acto impugnado; y los créditos provenientes de determinados contratos sinalagmáticos en que una de las partes obstaculiza el cumplimiento de la otra en perjuicio del concurso.

Por tanto, los créditos subordinados no responden a una misma lógica, lo que les caracteriza es su posición subordinada, pero no guardan aparentemente una relación entre $s^{39}$.

\section{SITUACIÓN DEL PRINCIPIO PAR CONDITIO CREDITORUM}

El Derecho concursal, como otras ramas del ordenamiento, configura con libertad (aunque sometido a los principios constitucionales y las normas sobre producción de otras normas) sus perfiles básicos. Los principios que lo ordenan quedan recogidos en la Ley Concursal, y de todos ellos destaca uno que aún no ha sido tratado como corresponde: el principio par conditio creditorum. La intención del legislador de incardinar esta idea fundamental en la LCon, queda patente en su Exposición de Motivos $^{40}$ : "Se considera que el principio de igualdad de tratamiento de los acreedores ha de constituir la regla general del concurso, y que sus excepciones han de ser muy contadas y siempre justificadas" (V). Aquí se hace alusión tanto a la regla general como a sus excepciones (privilegios), sin embargo, la postura que voy a desarrollar se aleja de esta concepción de igualdad de los acreedores, para exponer la manera en que dichas excepciones han terminado por corromper el principio par conditio creditorum.

En esta reflexión sobre la situación actual del aludido principio, será de particular interés el trabajo del profesor PEINADO GRACIA, que pone de relieve la libertad a la que se ha hecho mención. Pese a que nuestro sistema responde a un modelo

\footnotetext{
${ }^{38} \mathrm{La}$ "persona especialmente relacionada con el deudor" queda definida en el artículo 93 LCon, siendo el tipo de crédito que ha acaparado más atención de la doctrina dentro de esta categoría.

${ }^{39}$ FERRÉ FALCÓN, J., Los créditos... op. cit., pág. 166.

${ }^{40}$ También es mencionado en el artículo 162 LCon.
} 
eminentemente liberal $^{41}$ y no asistencial, la pluralidad de acreedores que se da en el concurso de acreedores no nos lleva irremisiblemente al principio par conditio creditorum. Su aparición en la Ley $22 / 2003$ es fruto de la elección y no puede entenderse como una exigencia de justicia: nada exige que se alterasen las reglas comunes del Derecho privado y se satisficiesen las obligaciones conforme al orden preconcursal (...) No existe un derecho subjetivo a la par conditio creditorum, tampoco existe una solidaridad ideal que conlleve la par conditio creditorum, sino que el Derecho concursal está encaminado a la cancelación de las obligaciones de los acreedores, y con ello a su satisfacción, pudiendo existir diversos medios para perseguir tal satisfacción ${ }^{42}$.

Vamos a mantener esta línea de razonamiento, la de un principio par conditio creditorum producto de una mera elección del legislador y proclamado sin demasiadas reservas por la doctrina; desmarcándonos de la óptica de la justicia, argumento que aborrece con solo mencionarlo en este ámbito del Derecho. Aceptada la regla general de la igualdad de los acreedores en el concurso, habrá que decir algo sobre sus excepciones. No interesa aquí desentrañar la naturaleza de los "privilegios" en el sistema concursal, no importa si se trata de un instituto procesal o si por el contrario son características inherentes al derecho de crédito (que parece menos posible). Lo que debe centrar nuestra atención son los efectos de dichos privilegios, su incidencia sobre la igualdad de los acreedores. A este respecto, la doctrina identifica el principio par conditio creditorum como la idea-fuerza del sistema concursal, debiendo darse varias notas (simultáneamente) para que sea admisible un privilegio que pervierta el orden general. Estas notas se concretan en la legalidad (exigencia de seguridad jurídica), necesidad (o causa suficiente) y excepcionalidad de los privilegios ${ }^{43}$.

\footnotetext{
${ }^{41}$ Donde el Derecho concursal es una forma más de extinción de las obligaciones del insolvente; y de forma supletoria, un sistema de identificación y supresión de empresas ineficientes.

42 PEINADO GRACIA, J. I., "La distribución del riesgo de insolvencia", Estudios sobre la Ley Concursal. Libro homenaje a Manuel Olivencia, Tomo I, Madrid, Marcial Pons, 2004, págs. 433 y $442-$ 443.

${ }^{43}$ Ibídem.
} 
Pero no podemos negar que pese a dichas notas, tales privilegios tienen un sentido absolutamente contrario al principio par conditio creditorum. La doctrina suele aceptar sin mayores reparos que algunos créditos queden por encima de otros en la liquidación concursal, cuando el legislador se funda en motivos de peso que hagan aconsejable determinar una excepción. Y esto es loable, sin embargo, como se ha dicho, el principio de igualdad de los acreedores en el concurso no es un dogma de fe, sino una elección del legislador, que si no va a respetar, podría eliminar del ordenamiento.

Esta "complacencia doctrinal" con la situación del principio que se analiza, viene en ocasiones determinada por la importante reducción de privilegios que tuvo lugar con la promulgación de la Ley Concursal. Sin embargo, no podemos quedarnos aquí. Que la LCon redujera el número de privilegios existentes antes de 2003 no puede ser visto como un mérito per se, ya que el principio par conditio creditorum es una apuesta de la Ley, y no una exigencia constitucional o de otro orden. Si bien comparto la conveniencia de esta simplificación que lleva a cabo el orden concursal actual, no puedo admitir que la igualdad de los acreedores en el concurso sea la regla general del procedimiento. Se ha analizado aquí el régimen de los créditos privilegiados y los subordinados (por no mencionar derechos de ejecución separada y otros institutos similares), observándose una amalgama de conceptos que poco tienen que ver con el principio par conditio creditorum y que se salen de lo estrictamente excepcional por importancia y número. En mi opinión, el principio que se analiza queda en una mera ilusión ante la vorágine de excepciones, anomalías y clasificaciones expuestas, que hacen tedioso el estudio de los créditos en el concurso de acreedores.

Algunos autores han mostrado cierta preocupación sobre este tema, SÁNCHEZ CALERO expresa sus dudas acerca de la cuestión señalando que la reducción de privilegios que tuvo lugar con la LCon es seguramente más modesta de lo que hubieran querido quienes redactaron el primer borrador (por la inclusión de ciertos privilegios a lo largo de la tramitación parlamentaria) ${ }^{44}$; por su parte, BROSETA PONT y MARTÍNEZ SANZ, aluden al principio par conditio creditorum diciendo que éste ha

\footnotetext{
${ }^{44}$ SÁNCHEZ CALERO, F., "La subordinación legal de créditos en caso de concurso de una sociedad", Estudios sobre la Ley Concursal. Libro homenaje a Manuel Olivencia, Tomo IV, Madrid, Marcial Pons, 2004, pág. 3895.
} 
de relativizarse, ya que es aplicable sólo a algunos acreedores, y por ello ha de aceptarse con reservas ${ }^{45}$.

Por tanto, se pone en duda la pertinencia de seguir manifestando como idea central del sistema concursal el principio par conditio creditorum. La cantidad de excepciones a esta regla general han terminado por difuminarla, haciéndola irreconocible. De manera que para dotar de sentido común y congruencia el ordenamiento concursal, el legislador podría tomar dos caminos:

- Desechar la igualdad de los acreedores como principio rector del concurso de acreedores, de acuerdo con la concepción de aquél como mera elección de política legislativa. En este sentido, ya que la par conditio creditorum no se está respetando, y siendo ésta una decisión del legislador, es preferible, antes de que se constate la ineficacia de la norma para obtener el fin que se propone, cambiar sus objetivos. La falta de adecuación entre el principio aludido y el articulado de la Ley es manifiesta. De forma que si la Ley responde a las exigencias de la sociedad en materia concursal, ¿por qué mantener la alusión a un principio que no puede operar dadas las prescripciones de la propia LCon? Desde esta postura, el legislador debería eliminar las -irrisoriasreferencias al principio par conditio creditorum, para proclamar el verdadero sistema que subyace en la LCon, que está basado en el privilegio de unos créditos sobre otros, configurándose como un sistema con una notable jerarquía de créditos.

- Reformular el principio par conditio creditorum, y que éste no se refiera al conjunto de acreedores, sino que actúe solo entre aquellos que se encuentren en el mismo nivel del orden de prelación de créditos. A veces se justifica la existencia de privilegios en base a la mayor diligencia de algunos acreedores. Por ejemplo, es el caso de los créditos con garantía real, se dice que el coste de dicha garantía legitima al acreedor a ser premiado con el privilegio especial en caso de concurso. Así, el acreedor que no toma las debidas precauciones, ve como su crédito no puede pasar de “ordinario". Al margen de que estas consideraciones no son del todo ciertas, dado que existen créditos privilegiados por motivos que poco tienen que ver con la diligencia del acreedor; podemos establecer una relación entre esta tesis y la posibilidad de reformular

${ }^{45}$ BROSETA PONT, M. y MARTÍNEZ SANZ, F., Manual... op. cit., pág. 594. 
la igualdad de los acreedores en el concurso. Bastaría con articular un nuevo par conditio creditorum, cuya eficacia se circunscriba a las relaciones entre acreedores de un mismo nivel de privilegio. Así se estaría promocionando la igualdad de los acreedores de manera más acorde con la realidad de la LCon, sin que esto suponga la renuncia a los privilegios que justificadamente el legislador ha recogido en sede concursal, sean cuales sean los motivos que lo hayan llevado a ello (diligencia u otro que estime oportuno).

No obstante, esta opción tiene un inconveniente fundamental, el riesgo de caer en una reiteración innecesaria. Los acreedores que se encuentran en el mismo escalón de la jerarquía de créditos puede decirse que están en condiciones idénticas respecto del procedimiento concursal. De manera que la tutela de la igualdad de éstos, ya es una realidad en virtud de la protección constitucional que otorga el artículo $1 \mathrm{CE}$ que propugna la igualdad como valor superior del ordenamiento jurídico; y el artículo 14 $\mathrm{CE}$, que establece la igualdad de todos los españoles ante la Ley.

\section{LA TÉCNICA CLASIFICATORIA: VALORACIÓN CRÍTICA}

La clasificación de créditos recién expuesta es una creación de la Ley 22/2003. La técnica utilizada por la LCon, como se ha podido ver, tiene algunas disfunciones. Recapitulando, podemos encontrar ciertas incongruencias que van a hacer surgir dudas sobre la pertinencia del método utilizado por la Ley. Tenemos una clasificación de créditos que discrimina con total nitidez aquellos que forman parte de la masa pasiva (los que han provocado el concurso) de los que son producto del mismo, esto es, los créditos contra la masa. En este punto, ya podemos identificar un importante problema teórico, puesto que en dicha categoría se han incluido créditos como los salariales (que además podrían haber sido reconducidos a otros institutos como el Fondo de Garantía Salarial $^{46}$, en pos de una cierta descarga del concurso), que no son producto del concurso sino que son parte del problema financiero del concursado. Por tanto, se está configurando el crédito contra la masa no como una figura extraconcursal, sino como un

${ }^{46}$ CANDELARIO MACÍAS, Mª I., Lecciones... op. cit., pág. 115. 
crédito superprivilegiado, por encima del resto de deudas, ya que se ha desvirtuado su naturaleza incluyendo este tipo de Derechos, que en puridad deberían ser concursales.

Por otro lado, a pesar de esta pretendida prioridad, la realización de créditos contra la masa debe respetar aquellos bienes que garantizan créditos especialmente privilegiados. De nuevo estamos ante una paradoja, si los créditos contra la masa son prededucibles y prioritarios, ¿cómo pueden estar limitados por los créditos con privilegio especial? Este problema de la afectación de bienes al pago de determinados créditos podría haberse resuelto eliminando este privilegio especial, otorgando a los créditos garantizados en este sentido un derecho de ejecución separada como ocurre con buques y aeronaves. Su inclusión en la masa pasiva del concurso es del todo confusa pues no se respeta la proclamada prioridad de los créditos contra la masa. Otra opción sería, entendiendo que el sistema ha mutado, incluir los créditos contra la masa (con otra denominación) entre los concursales. Ya no representan únicamente los costes del procedimiento, manifestándose que su posición no es de prelación a la hora del pago a los acreedores, sino que suponen un segundo escalón tras los créditos especialmente privilegiados. Con estos planteamientos, no se está olvidando que los créditos contra la masa se satisfacen a su vencimiento, simplemente se está analizando la norma desde otro plano que no es el temporal, sino el de la satisfacción efectiva de los créditos, que en situaciones de concurso resulta más importante y es el que determinará si un acreedor es privilegiado o no.

Las dificultades creadas por la técnica utilizada para ordenar los créditos del deudor concursado producen una inseguridad, al menos en el plano teórico, que no favorece en absoluto la comprensión de la institución ni sus objetivos. Éstos quedan totalmente desdibujados cuando es posible que para el operador jurídico surjan dudas acerca de qué es lo que ha intentado el legislador concursal proteger en primer lugar, qué créditos son los que quedan en una posición superior y cuáles son los motivos para priorizarlos.

Todo ello redunda en una clara violación del principio par conditio creditorum, que se acogió tímidamente por el legislador, pero que no ha sido llevado a la práctica tal y como se ha expuesto. La igualdad de los acreedores es cuanto menos un mito en 
nuestro ordenamiento, ya que lo que se constata es todo lo contrario: la jerarquía y el privilegio en relación la satisfacción de los créditos del concursado. 